\title{
Effect of improved metabolic control on loss of kidney function in Type 1 (insulin-dependent) diabetic patients: an update of the Steno studies
}

\author{
B. Feldt-Rasmussen, E. R. Mathiesen, T.Jensen, T. Lauritzen and T. Deckert \\ Steno Memorial Hospital, Gentofte, Denmark
}

\begin{abstract}
Summary. We re-examined 69 of the 70 patients entering the two independent Steno Studies of effects of improved metabolic control on progression of late diabetic complications. They were analysed according to an intent to treat after follow-up for 8 years (Steno Study 1) and 5 years (Steno Study 2). The glycaemic control had improved in the insulin infusion group compared with the conventional treatment group (mean $\mathrm{HbA}_{1 \mathrm{c}}$ ) by $2.0 \pm 0.6 \%$ vs $0.7 \pm 1.2$ in Steno Study 1 and by $1.8 \pm 1.2 \%$ vs $0.4 \pm 1.3(p<0.01)$ in Steno Study 2 . In the insulin infusion groups three patients had died during episodes of ketoacidosis. These were not caused by malfunction of the insulin infusion pumps. In the conventional treatment groups, three patients suffered five cardiovascular events causing two deaths. From the sixth month of Steno Study 1 the annual change of the glomerular filtration rate was $-3.7(-5.4$ to -2.0$) \mathrm{ml} \cdot \mathrm{min}^{-1} .1 .73 \mathrm{~m}^{-2} \mathrm{vs}-1.0$ $(-2.1$ to -0.1$)$ (conventional vs insulin infusion group, mean $(95 \%$ confidence interval, $p<0.01)$ ). The change in
\end{abstract}

urinary albumin excretion was associated with the glycaemic control $(n=69, r=0.49, p<0.0002)$. No progression was observed among 32 patients with low range microalbuminuria ( 30 to $99 \mathrm{mg} / 24 \mathrm{~h}$ ). Among the 19 patients with an initial albumin excretion between 100 and $300 \mathrm{mg} / 24 \mathrm{~h}$, progression of complications was more frequent during conventional treatment $(n=10)$ vs insulin infusion $(n=9)$ : Clinical nephropathy ( 10 of 10 vs 2 of $9, p<0.01$ ) and arterial hypertension ( 7 of 10 vs 1 of $9, p<0.01$ ). The glomerular filtration rate declined during conventional treatment by $-23(-42$ to $-4) \mathrm{ml} \cdot \mathrm{mm}^{-1} \cdot 1.73 \mathrm{~m}^{-2}(p<0.05)$ but not during insulin infusion ( $-13(-31$ to 5$)$ NS). These results suggest that patients at risk of nephropathy should be offered near normal glycaemic control in order to preserve their kidney function.

Key words: Type 1 (insulin-dependent) diabetes mellitus, $\mathrm{HbA}_{1 \mathrm{c}}$, microalbuminuria, insulin infusion pumps, continuous subcutaneous insulin infusion, blood pressure.
The effects of improved metabolic control on the development and progression of microvascular complications in Type 1 (insulin-dependent) diabetic patients have been studied in a number of prospective randomized trials. Only some of these have been in progress for one year or more [1-11]. If the lesions in question were not too advanced at entry $[5,7]$, these studies have demonstrated beneficial effects of improved metabolic control on various morphological and physiological markers of microangiopathy and neuropathy [1-4, 6, 8-11]. Such effects are likely also to delay or prevent loss of kidney function and vision but this was never demonstrated because of small numbers of patients studied and study periods too short for significant clinical progression to occur in either intensive treatment or control groups. Attaching the greatest importance to kidney function we have readdressed this important question and re-examined 69 of the 70 Type 1 diabetic patients who entered one of the two independent Steno Studies of improved vs unchanged metabolic control in 1980 [1] or in 1983 [2].

\section{Subjects and methods}

\section{Subjects}

The subjects were 70 patients with Type 1 diabetes who fulfilled the following criteria: Age 18-51 years, postprandial C-peptide level $<0.2 \mathrm{nmol} / \mathrm{h}$, history of diabetes $5-35$ years, diabetes onset before age 30 , serum creatinine $<150 \mu \mathrm{mol} / \mathrm{l}$ and no history of non-diabetic renal disease. In 198034 entered the Steno Study 1 [1] and in 198336 entered the Steno Study 2 [2]. The patients gave their informed consent and the protocols were approved by the regional scientific ethical committee. Steno Study 1 [1] had the additional entrance criterion of presence of background retinopathy. Shortly after randomization, one patient in each group turned out to have minor proliferative changes. One in the insulin infusion group had well regulated hypertension treated with hydroflumethiazide, $25 \mathrm{mg}$ daily. No other patients took any medication besides insulin. All were included in the present study.

In Steno Study 2 [2] the additional entrance criterion was a urinary albumin excretion rate in the range of $30-300 \mathrm{mg} / 24 \mathrm{~h}$ in two of three $24 \mathrm{~h}$ urine specimens collected at home over a 3-month period, supine systolic blood pressure $<160 \mathrm{~mm} \mathrm{Hg}$ and diastolic blood 
pressure $<95 \mathrm{~mm} \mathrm{Hg}$. One patient with anorexia nervosa did not recover before moving to another part of the country and was the only patient excluded from this follow-up. The study, therefore, comprised 69 patients.

\section{Random assignment}

In both studies, the 69 patients had been assigned randomly to either continuous subcutaneous insulin infusion or to remain on conventional insulin treatment. The two groups were well matched in key demographic and clinical data $[1,12]$, apart from differences explained by the different entrance criteria. After the two-year reports $[1,2]$ the patients could freely choose between conventional insulin treatment with one or two insulin injections per day, multiple injections with four injections per day, and continuous subcutaneous insulin infusion by means of portable insulin infusion pumps.

\section{Diabetic control}

The metabolic control was monitored by measuring glycosylated haemoglobin (haemoglobin $\mathrm{HbA}_{\text {ic }}$, reference range 5.4-6.3\% [13]) every other month during study and at least four times a year throughout the follow-up period. The long-term (years) glycaemic control of each patient was estimated by first calculating the annual median of all $\mathrm{HbA}_{1 \mathrm{c}}$ measurements through that year, and then calculating for each patient the mean of these values, (hereafter called the mean of all $\mathrm{HbA}_{\mathrm{lc}}$ values). Patients on the intensified treatment regimens adjusted their insulin dose according to blood glucose measurements at home using blood glucose stix (BM-Test-Glycemic 1-44 Boehringer Mannheim GmbH, FRG), or Haemo-Glukotest 1-44, (Boehringer). After two years of study the patients continued their regular visits at the outpatients' clinic of the Steno Menorial Hospital, but the check-up on the frequency of blood glucose measurements at home was not continued. In case of acute illness or high blood glucose the use of ketostix were strongly and repeatedly recommended and in case of doubt the patients were asked to contact the hospital.

\section{Laboratory measurements and ophthalmoscopy}

Urinary albumin concentration was initially measured by a radial immunodiffusion technique [14] to examine one or two sterile $24 \mathrm{~h}$ urine specimens collected at home every other month. Since 1985 an ELISA technique tested against the previous technique [15] was used.

Blood pressure in the right arm was measured every second month with a standard sphygmomanometer ( 25 by $12 \mathrm{~cm}$ cuff) after 20 min of lying at rest. The diastolic blood pressure was recorded at disappearance of the Korotkoff sounds (phase 5). The glomerular filtration rate was assessed at $0,6,12,24$ months and at re-examination five or eight years after randomization by measuring plasma disappearance of a single i.v. injection of $\left({ }^{51} \mathrm{Cr}\right.$ ) edetic acid (given at 09.00 hours) over a period of $4 \mathrm{~h}$ [16]. Patients were examined with an ophthalmoscope through the dilated pupilla at entry to the study and at re-examination.

\section{Endpoints}

These were death, major cardiovascular events, decline in glomerular filtration rate, blood pressure increase persistently above $160 / 95 \mathrm{~mm} \mathrm{Hg}$ (with subsequent start of antihypertensive treatment), urinary albumin excretion rate above $300 \mathrm{mg} / 24 \mathrm{~h}$ in two out of three $24 \mathrm{~h}$ urine collections and development of proliferative retinopathy. Results are given at re-examination or as the last reading before death. If antihypertensive treatment was started, the data on blood pressure and urinary albumin excretion rates are given as median of the last three readings prior to treatment.

\section{Analysis of patients with microalbuminuria}

An analysis was performed on the 51 patients from the two studies who at entry had no nephropathy but an elevated urinary albumin excretion rate ranging from 30 to $300 \mathrm{mg} / 24 \mathrm{~h}$ in at least two out of three $24 \mathrm{~h}$ urine samples (microalbuminuria). They were subdivided according to presence of low range ( 30 to $99 \mathrm{mg} / 24 \mathrm{~h}, n=32$ ) or high range ( 100 to $300 \mathrm{mg} / 24 \mathrm{~h}, n=19$ ) microalbuminuria and were analysed according to the original randomization of Steno Study 1 and 2 (Table 4). This subdivision was made because our previous prospective study of the discriminative level of urinary albumin excretion had shown that all patients with a urinary albumin excretion above $70 \mu \mathrm{g} / \mathrm{min}=100 \mathrm{mg} / 24 \mathrm{~h}$ progressed to nephropathy within seven years [17] whereas few patients with microalbuminuria in the low range of 30 to $99 \mathrm{mg} / 24 \mathrm{~h}$ progressed. Patients in the subgroups were similar with respect to age, diabetes duration and at entry had similar $\mathrm{Hb}_{1 \mathrm{c}}$, glomerular filtration rate and blood pressure (Table 4).

\section{Statistical methods}

Data are given as mean with SD or $95 \%$ confidence interval. Urinary albumin excretion were log transformed before analyses and given as geometric mean with $95 \%$ confidence interval. Paired and unpaired Student's $t$-test and Fisher's exact test were used for comparisons within and between the groups. Multiple stepwise regression analysis including all patients were performed with a commercially available program (Statgraphic, STSC, Rockvill, Md., USA). Levels of significance were set to $p<0.05$ (two tailed).

\section{Results}

\section{Glycaemic control}

The glycaemic control is given as the mean of all $\mathrm{HbA}_{1 c}$ values measured in each patient during the entire study and follow-up period. It had significantly improved in the original insulin infusion groups compared with the conventional treatment groups (Table 1). Eighteen patients had changed their form of treatment during the third to fourth year of follow-up, and metabolic control during the last three years prior to the re-examination was no longer distinguishable between the original groups (Table 1). An overall trial effect was observed. Thus, the 33 patients in the conventional treatment groups improved their mean $\mathrm{HbA}_{1 \mathrm{c}}$ during the entire study by $0.6 \%$ (95\% confidence

Table 1. Steno studies 1 and 2. A five and eight years follow-up. Metabolic control, actual treatment

\begin{tabular}{|c|c|c|c|c|}
\hline & Steno 1 & & Steno 2 & \\
\hline $\begin{array}{l}\text { Original } \\
\text { treatment }\end{array}$ & CSII & CIT & CSII & $\mathrm{CIT}$ \\
\hline Numbers studied & 18 & 16 & 18 & 17 \\
\hline $\begin{array}{l}\mathrm{HbA}_{1 c}(\%) \\
\text { At entry }\end{array}$ & $9.6 \pm 1.6$ & $8.8 \pm 1.4$ & $9.6 \pm 2.0$ & $9.1 \pm 1.2$ \\
\hline Mean of all $\mathrm{HbA}_{1 \mathrm{c}}$ & $7.6 \pm 0.9$ & $8.1 \pm 1.1$ & $7.9 \pm 1.1$ & $8.8 \pm 1.0$ \\
\hline$\Delta \mathrm{HbA}_{\mathrm{ic}}$ & $2.0^{\mathrm{a}} \pm 0.6$ & $0.7 \pm 1.2$ & $1.8^{\mathrm{a}} \pm 1.2$ & $0.4 \pm 1.3$ \\
\hline $\begin{array}{l}\text { Mean during } \\
\text { last } 3 \text { years }\end{array}$ & $7.9 \pm 1.0$ & $7.9 \pm 1.3$ & $8.2 \pm 1.2$ & $8.7 \pm 1.3$ \\
\hline $\begin{array}{l}\text { Insulin dose } \\
\text { (U/kg) at last } \\
\text { examination }\end{array}$ & $\begin{array}{l}0.53 \\
(0.30-0.85)\end{array}$ & $\begin{array}{l}0.53 \\
(0.39-0.70)\end{array}$ & $\begin{array}{l}0.50 \\
(0.33-1.21)\end{array}$ & $\begin{array}{l}0.55 \\
(0.23-1.10)\end{array}$ \\
\hline
\end{tabular}

Form of treatment ${ }^{b}$

at re-examination

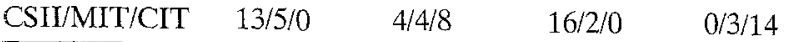

Mean \pm 1 SD or range in parentheses.

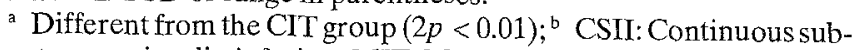
cutaneous insulin infusion. MIT: Multiple injection treatment. CIT: Conventional insulin treatment 
Table 2. Steno Studies 1 and 2. A five and eight years follow-up. Major endpoints

\begin{tabular}{|c|c|c|c|c|}
\hline & Steno 1 & & Steno & \\
\hline Original treatment & CSII & $\mathrm{CIT}$ & CSII & CIT \\
\hline Numbers studied: & 18 & 16 & 18 & 17 \\
\hline $\begin{array}{l}\text { Nephropathy: } \\
\text { (normal/microalbut }\end{array}$ & $\mathrm{ia} / \mathrm{clinic}$ & ephrol & & \\
\hline At entry & $8 / 9 / 1$ & $6 / 7 / 3$ & $0 / 18 / 0$ & $0 / 17 / 0$ \\
\hline At re-examination & $10 / 6 / 2$ & $7 / 1 / 8$ & $6 / 11 / 1$ & $6 / 6 / 5$ \\
\hline $\begin{array}{l}\text { Retinopathy: } \\
\text { (nil/background/pro }\end{array}$ & ative) & & & \\
\hline At entry & $0 / 17 / 1$ & $0 / 15 / 1$ & $5 / 12 / 1$ & $5 / 11 / 1$ \\
\hline At re-examination & $0 / 12 / 6$ & $0 / 7 / 9$ & $4 / 12 / 2$ & $2 / 12 / 3$ \\
\hline Antihypertensive tre & ent: & & & \\
\hline At entry & 1 & 0 & 0 & 0 \\
\hline At re-examination & 5 & 8 & 2 & 3 \\
\hline
\end{tabular}

CSII: Continuous subcutaneous insulin infusion. CIT: Conventional insulin treatment

interval -1 to $-0.1 \%, p=0.013)$. The insulin dose was similar in the four groups (Table 1).

\section{Hypoglycaemia and ketoacidosis}

In the insulin infusion groups the overall frequencies of ketoacidotic (0.09 per patient-year) and hypoglycaemic episodes ( 0.10 per patient-year) requiring medical intervention during the last year were similar to our previous reports.

Three patients had died during diabetic ketoacidosis confirmed biochemically upon post mortem.

Case no. 1. (Steno Study 2). A 36-year-old male with a diabetes duration of 16 years, a mean $\mathrm{HbA}_{1 \mathrm{c}}$ of $8.0 \%$ and an initial and last urinary albumin excretion rate of 63 and $96 \mathrm{mg} / 24 \mathrm{~h}$. He apparently developed pneumonia and was treated with antibiotics by a general practitioner. The hospital was not informed. The patient persistently informed the family and various doctors on house calls that the diabetes was under control, until he acutely deteriorated and died in respiratory failure (presumably Kussmauls respiration) in an ambulance. Autopsy revealed not pneumonia but an enlarged heart with increased amounts of connective tissue, indicating cardiomyopathy. The insulin infusion pump was operating impeccably.

Case no.2. (Steno Study 2). A 32-year-old male with a diabetes duration of 16 years, a urinary albumin excretion rate of 33 to $25 \mathrm{mg} / 24 \mathrm{~h}$ and a mean $\mathrm{HbA}_{1 \mathrm{c}}$ of $9.2 \%$. He had recently been divorced and was receiving psychiatric therapy after having attempted suicide. He was living alone and was found dead in his bed with signs of previous excitation. The insulin infusion pump was operating impeccably with the connecting tubes seemingly intact. Post mortem examination did not reveal the cause of death.

Case no.3. (Steno Study 1) A 25-year-old male with a diabetes duration of 24 years who was living alone. The urinary albumin excretion rate at entry and during the study were 179 to $200 \mathrm{mg} / 24 \mathrm{~h}$, the mean $\mathrm{HbA}_{\mathrm{lc}}$ was
$6.4 \%$. The patient suffered from proliferative retinopathy with a progressive loss of vision and had, in consequence, recently lost his job. He was found dead without objective signs of convulsions. The pump was operating impeccably but had been disconnected and was neatly placed on a table beside the bed. Biochemical examination of blood and urine was performed but no post mortem examination.

\section{Cardiovascular events}

Three patients in the conventional treatment group of Steno Study 2 and one initially receiving insulin infusion in Steno Study 1 suffered six severe cardiovascular events during which two of the patients died.

Case no.1. A 44-year-old female with diabetes for 23 years, a urinary albumin excretion rate of $68-85 \mathrm{mg} / 24 \mathrm{~h}$, a mean $\mathrm{HbA}_{1 \mathrm{c}}$ of $8.6 \%$ and receiving antihypertensive treatment had a lethal pulmonary embolism of unknown origin.

Case no.2. A 46-year-old male with diabetes for 31 years, a urinary albumin excretion rate of 180 to $313 \mathrm{mg} / 24 \mathrm{~h}$, a mean $\mathrm{HbA}_{1 \mathrm{c}}$ of $8.6 \%$ and receiving antihypertensive treatment had three cerebro-vascular accidents within one year and died during the last episode.

Case no.3. A 52-year-old male with diabetes for 23 years, a urinary albumin excretion rate of 66 to $41 \mathrm{mg} / 24 \mathrm{~h}$, a mean $\mathrm{HbA}_{1 \mathrm{c}}$ of $8.6 \%$ and a blood pressure of $145 / 90 \mathrm{mmHg}$, receiving no antihypertensive treatment. A minor cerebro-vascular accident of the left cerebral hemisphere caused a partial hemiparesis with almost complete remission after 4 weeks.

Case no.4. (Steno Study 1) A 55-year-old female with diabetes for 27 years and a urinary albumin excretion rate over $1000 \mathrm{mg} / 24 \mathrm{~h}$ at entry, declining to persistently below $300 \mathrm{mg} / 24 \mathrm{~h}$ after introduction of antihypertensive treatment. She received insulin infusion for two years $\left(\mathrm{HbA}_{10}\right.$ $7.3 \%$ ) but then changed to multiple injections ( $\mathrm{HbA}_{10}$ $10.1 \%$ ). The patient survived a subendocardial infarction in 1985 .

\section{Nephropathy, blood pressure and retinopathy}

In both studies, Steno 1 and 2, the number of patients progressing to clinical nephropathy, proliferative retinopathy or developing hypertension were higher in the conventional treatment groups compared with the insulin infusion groups (Table 2). None of these differences, however, reached statistical significance when analysing the two studies separately.

The systolic blood pressure increased significantly $(p<0.05)$ in the conventional treatment groups of both studies but not during insulin infusion (Table 3 ). In both studies more than half of the patients had a stable urinary albumin excretion rate or even normalized a slightly elevated one (Steno 2, six patients in each treatment group, Table 2). Only one patient progressed from normal to microalbuminuria and progression from normoalbuminu- 


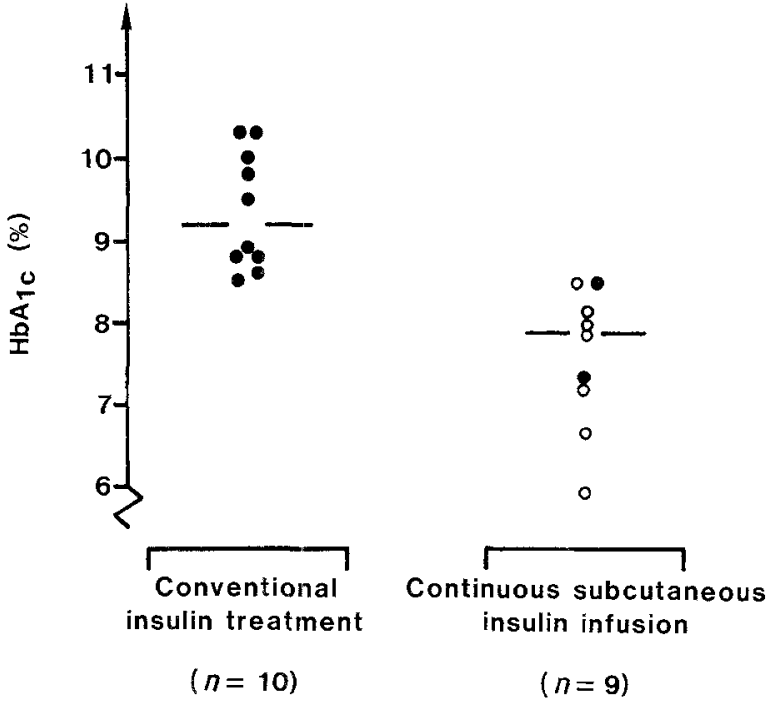

Fig. 1. Metabolic control during a mean of seven years of observation in 19 Type 1 (insulin-dependent) diabetic patients who had a urinary albumin excretion between 100 and $300 \mathrm{mg} / 24 \mathrm{~h}$ when entering one or other of the two Steno studies. The $\mathrm{HbA}_{1 c}$ value for each patient is given as the mean of annual medians of all measurements during study. Closed circles: Patients progressing to clinical nephropathy. Significant difference between groups $(p<0.001)$. All nine patients randomized to receive continuous subcutaneous insulin treatment remained on this treatment. Among the ten in the original. conventional treatment group, one had changed to continuous insulin infusion (mean $\mathrm{HbA}_{1 \varepsilon} 8.5 \%$ ) and two received multiple insulin injections $\left(\mathrm{HbA}_{l c} 8.9 \%\right.$ and $\left.9.4 \%\right)$

ria to clinical nephropathy was not observed. The differences in urinary albumin excretion between the insulin infusion and the conventional treatment groups at reexamination were not significant (Table 3 ). The glomerular filtration rate declined significantly in both treatment groups of Steno Study 1 (Table 3). In the insulin infusion group of Steno Study 1 a decline in the glomerular filtration rate had been observed during the first 6 months of study $\left(124 \pm 28 \mathrm{ml} \cdot \mathrm{min}^{-1} \cdot 1.73 \mathrm{~m}^{-2}\right.$ to $114 \pm 24(p<0.05)$ as a response to the improvement of the metabolic control, with a mean reduction of $\mathrm{HbA}_{1 \mathrm{c}}$ of $2 \%$. The glomerular filtration rate thereafter remained stable for the following 7 years and six months. In the conventional treatment group no change was observed at 6 months $\left(113 \pm 15 \mathrm{ml} \cdot \mathrm{min}^{-1} \cdot 1.73 \mathrm{~m}^{-2}\right.$ to $115 \pm 15$ (NS)). When, therefore, using the glomerular filtration rate at six months as the initial value, a difference between the groups was observed: The reduction was $-28(-41$ to -15) $\mathrm{ml} \cdot \mathrm{min}^{-1} \cdot 1.73 \mathrm{~m}^{-2}$ in the conventional treatment group and $-8(-16$ to 0$)$ in the insulin infusion group ( $p<0.01$ between groups). The annual change was -3.7 $(-5.4$ to -2.0$) \mathrm{ml} \cdot \mathrm{min}^{-1} \cdot 1.73 \mathrm{~m}^{-2}$ vs $-1.0(-2.1$ to $-0.1)(p<0.01)$. No significant change in the glomerular filtration rate was observed during 5 years follow-up in Steno Study 2 (Table 3).

A multiple regression analysis of all 69 patients was performed with the urinary albumin excretion rate at reexamination as the dependent variable. Independent variables of significance were the initial urinary albumin excretion rate $(p<0.0001)$ and the mean $\mathrm{HbA}_{1 \mathrm{c}}$ during study $(p<0.01)$. Of no influence were age, diabetes duration and initial values of $\mathrm{HbA}_{1 c}$, glomerular filtration rate and systolic as well as diastolic blood pressure. Mean $\mathrm{HbA}_{1 \mathrm{c}}$ was the major determinant when testing the change in urinary albumin excretion rates $(p<0.01)$ and this change was also associated with the glomerular filtration rate at entry $(p<0.05)$. The change in glomerular filtration rate (at re-examination vs at entry) was also dependent on the initial glomerular filtration rate $(p<0.0001)$, urinary albumin excretion rate $(p<0.01)$ and on diastolic blood pressure $(p<0.05)$. An association with $\mathrm{HbA}_{1 c}$ was not expressed.

Combined analysis of 51 patients with microalbuminuria at entry demonstrated that only one of 32 with low range microalbuminuria $(65 \mathrm{mg} / 24 \mathrm{~h}$, mean $\mathrm{HbA}$ $8.3 \%$ ) progressed to clinical nephropathy (Table 4 ). In contrast, a significant progression was observed among the 19 patients at severe risk of nephropathy with an initial urinary albumin excretion rate ranging from 100 to $300 \mathrm{mg} / 24 \mathrm{~h}$ at entry to Steno Study $1(n=8)$ and to Steno Study $2(n=11)$. Nine patients had been randomized to receive insulin infusion and 10 to the conventional treatment groups (Table 4). In the insulin infusion group 2 of the 9 developed clinical nephropathy vs 10 of 10 in the control group $(p<0.001$, Table 4$)$. In the conventional treatment group the urinary albumin excretion rate was increasing $(p<0.05)$ and the glomerular filtration rate declining ( $p<0.05$, Table 4 and Fig. 2$)$. Also, in that group the systolic blood pressure increased significantly and arterial hypertension was diagnosed more frequently $(p<0.01$, Table 4$)$. In the insulin infusion group no significant changes took place. The long-term glycaemic control given as individual $\mathrm{HbA}_{1 \mathrm{c}}$. values (mean of 7 years) of these 19 patients are shown in Figure 1.

There were no significant changes in visual acuity within or between groups at re-examination. During conventional treatment 23 of 33 patients had a normal visual

Table 3. Steno studies 1 and 2. A five and eight years follow-up. Effects of improved metabolic control on urinary albumin excretion rate, glomerular filtration rate and blood pressure

\begin{tabular}{|c|c|c|c|c|}
\hline & Steno 1 & & Steno 2 & \\
\hline Original treatment & CSII & $\mathrm{CIT}$ & CSII & CIT \\
\hline \multicolumn{5}{|c|}{ Urinary albumin excretion $(\mathrm{mg} / 24 \mathrm{~h})$ : } \\
\hline Atentry & $43(21-91)$ & $73(30-134)$ & $73(51-104)$ & $65(45-95)$ \\
\hline At re-examination & $33(15-72)$ & $122(33-444)$ & $62(38-102)$ & $72(27-186)$ \\
\hline \multicolumn{5}{|c|}{ Glomerular filtration rate (GFR): $\left(\mathrm{ml} \cdot \mathrm{min}^{-1} \cdot 1.73 \mathrm{~m}^{-2}\right)$} \\
\hline Atentry & $124 \pm 28$ & $113 \pm 15$ & $109 \pm 19$ & $113 \pm 21$ \\
\hline At re-examination & $106 \pm 27^{b}$ & $87 \pm 26^{b}$ & $108 \pm 22$ & $113 \pm 22$ \\
\hline GFR (last-first) & $\begin{array}{l}-18 \\
(-28 \text { to }-8\end{array}$ & $\begin{array}{l}-26 \\
(-40 \text { to }-12)\end{array}$ & $\begin{array}{l}-1 \\
(-9 \text { to }+9)\end{array}$ & $\begin{array}{l}0 \\
(-7 \text { to }+5)\end{array}$ \\
\hline \multicolumn{5}{|c|}{ Blood pressure ( $\mathrm{mmHg}$ ) } \\
\hline \multicolumn{5}{|l|}{ At entry } \\
\hline $\begin{array}{l}\text { systolic } \\
\text { diastolic }\end{array}$ & $\begin{array}{c}132 \pm 14 \\
85 \pm 6\end{array}$ & $\begin{array}{c}126 \pm 13 \\
85 \pm 9\end{array}$ & $\begin{array}{c}128 \pm 13 \\
83 \pm 5\end{array}$ & $\begin{array}{c}128 \pm 12 \\
82 \pm 8\end{array}$ \\
\hline \multicolumn{5}{|l|}{ At re-examination } \\
\hline $\begin{array}{l}\text { systolic } \\
\text { diastolic }\end{array}$ & $\begin{array}{r}137 \pm 22 \\
83 \pm 11\end{array}$ & $\begin{aligned} 137 & \pm 24^{\mathrm{a}} \\
87 & \pm 9\end{aligned}$ & $\begin{array}{r}132 \pm 18 \\
81 \pm 11\end{array}$ & $\begin{array}{c}136 \pm 14^{a} \\
86 \pm 11\end{array}$ \\
\hline
\end{tabular}

CSII: Continuous subcutaneous insulin infusion. CIT: Conventional insulin treatment. Mean \pm SD or logarithmic mean with $95 \%$ confidence interval.

a Significant deterioration compared with initial examination, $2 p<0.05$; ${ }^{b}$ Significant deterioration compared with initial examination, $2 p<0.01$ 


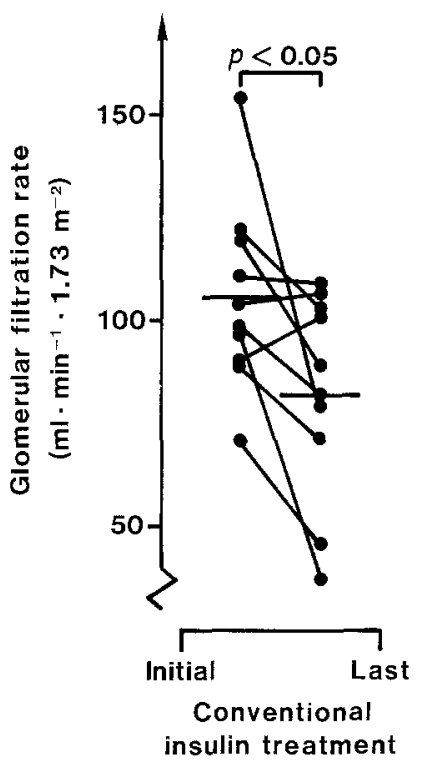

$(n=10)$
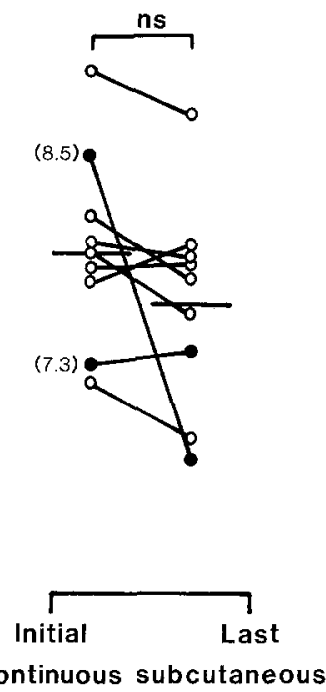
insulin infusion

$(n=9)$
Fig. 2. Glomerular filtration rate at entry and at re-examination. Same 19 patients as in Figure 1. Closed circles: Patients progressing to clinical nephropathy. Horisontal bars: Mean values. In parentheses: mean $\mathrm{HbA}_{1 \mathrm{c}}$ during study, given for the two patients progressing to nephropathy

acuity of $6 / 6$ on both eyes. Three eyes of two patients had a visual acuity worse than $6 / 60$. The numbers during insulin infusion were 27 out of 36 and four eyes of two patients worse than $6 / 60$.

\section{Discussion}

This study has confirmed our original observation after two years of an association between long-term glycaemic control $\left(\mathrm{HbA}_{1 c}\right)$ and change in urinary albumin excretion in Type 1 diabetic patients with clinical signs of microangiopathy [2]. It has also confirmed that blood pressure, though significantly increasing in the conventional treatment group, remains unchanged during insulin infusion [2]. As a new observation, the present results suggest that the rate of decline of the glomerular filtration rate can be reduced during several years of improved metabolic control. This was indicated after eight years of follow-up in Steno Study 1 when analysing according to an intent to treat, i.e. with the patients in the original randomized treatment groups. The number of patients with a normal urinary albumin excretion rate, microalbuminuria or nephropathy were similar between the groups after randomization with no difference in the urinary albumin excretion at entry (Table 2). Despite the randomization patients in the insulin infusion group tended to have higher glomerular filtration rates at entry, possibly a glomerular hyperfiltration related to their (insignificantly) higher $\mathrm{HbA}_{\mathrm{lc}}$ values at entry. Six months later when the glycaemic control had been improved, their glomerular filtration rate had been normalized to the level of the control group [18] and thereafter remained stable for 7 years and 6 months. If the results were reasonably analysed with the glomerular filtration rates at 6 months vs eight years the annual change was $-3.7(-5.4$ to 2.0$) \mathrm{ml} \cdot \mathrm{min}^{-1}$. $1.73^{-2}$ in the conventional treatment group $(p<0.01)$ vs

Table 4. Combined analysis of all 51 Type 1 (insulin-dependent) diabetic patients with microalbuminuria $(30-300 \mathrm{mg} / 24 \mathrm{~h})$, at entry of the Steno Studies ( 5 to 8 years follow-up)

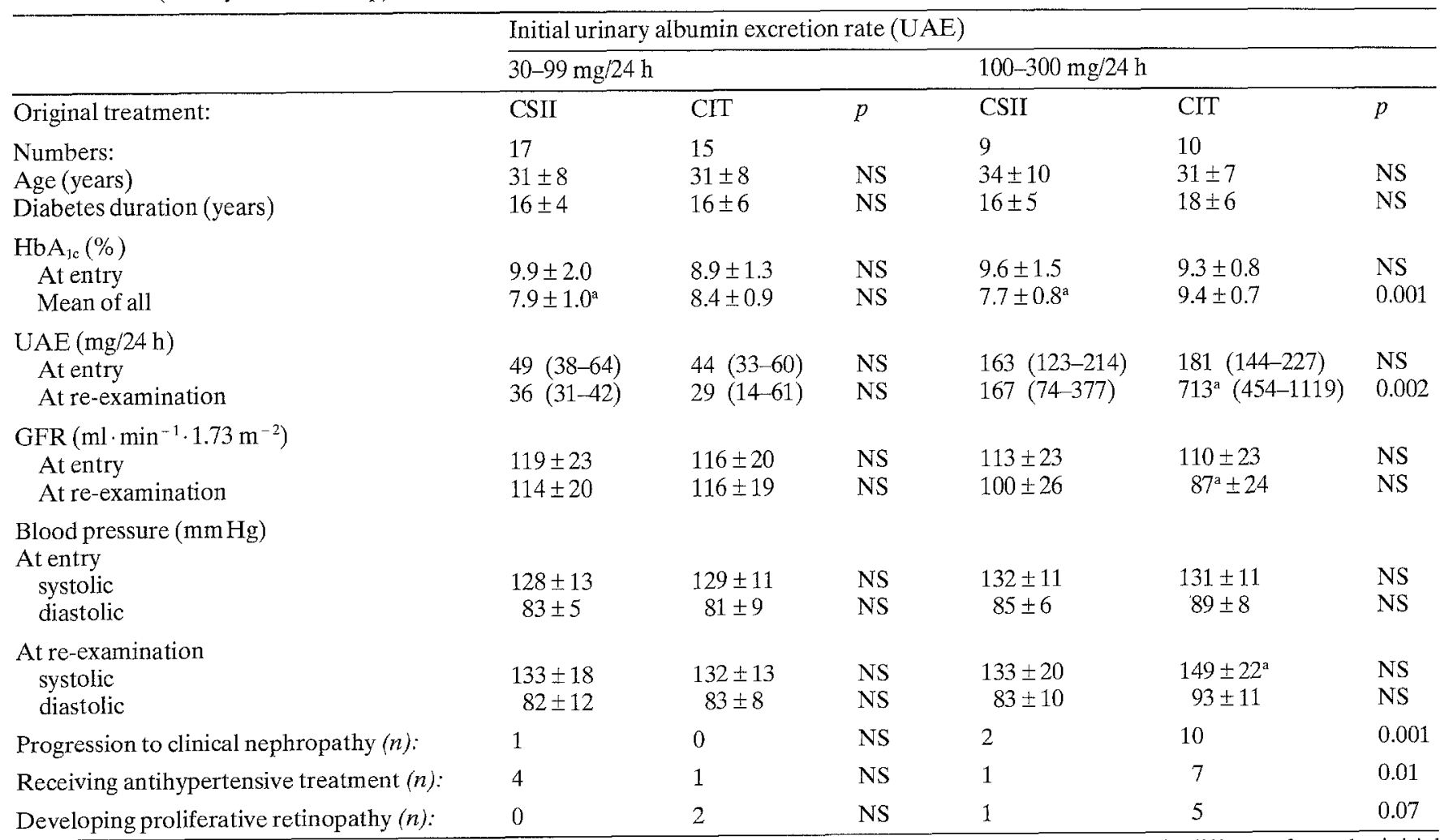

Mean \pm SD or logarithmic mean with $95 \%$ confidence interval. GFR: Glomerular filtration rate. ${ }^{\text {a }}$ Significantly different from the initial value, $2 p<0.05$ 
$-1.0(-2.1$ to 0.1$)$ during insulin infusion (NS) $(p<0.01$ between groups).

From both Steno Studies all 10 patients in the conventional treatment groups with an initial urinary albumin excretion rate of 100 to $300 \mathrm{mg} / 24 \mathrm{~h}$ progressed to clinical nephropathy whereas only one of the 46 patients included with an albumin excretion rate below $100 \mathrm{mg} / 24 \mathrm{~h}$ $(65 \mathrm{mg} / 24 \mathrm{~h})$ progressed, supporting previous observations by our group [17]. When separating the 51 patients who at entry had microalbuminuria (excluding those with normal albumin excretion $(n=14)$ or clinical nephropathy $(n=4)$ no significant progress of disease for a median of seven years in either treatment group could be demonstrated among patients with microalbuminuria in the low range. One patient developed clinical nephropathy (mean $\mathrm{Hb}_{1 \mathrm{c}}$ of $8.3 \%$ ) but 15 normalized their albumin excretion rates. It is a new observation that the glomerular filtration rate and the blood pressure remain stable for so many years in patients with microalbuminuria ranging from 30 to $99 \mathrm{mg} / 24 \mathrm{~h}$ when observed and treated as in this trial, i.e. with a fair but not "near-normalized" metabolic control, frequent blood pressure readings and institution of antihypertensive treatment at readings persistently above $160 / 95 \mathrm{~mm} \mathrm{Hg}$.

When analysing the patients with albumin excretion rates from $100-300 \mathrm{mg} / 24 \mathrm{~h}$ according to an intent to treat there was a significant difference between the metabolic control of the two treatment groups for a median of seven years. $\mathrm{Hb}_{1 \mathrm{c}}$, urinary albumin excretion, glomerular filtration rate and blood pressure was similar at entry. The above indication of an effect on the rate of decline of the glomerular filtration rate received strong support. Two patients in the insulin infusion groups progressed to nephropathy but the glomerular filtration rate was significantly reduced only in the conventional treatment group and not during insulin infusion. In this small subset this significant deterioration within the conventional treatment group occurred without significant differences between the groups at re-examination. This may be due to the variability of the glomerular filtration rate within the small groups of only 10 and 9 patients (type 2 error). At re-examination, however, more patients in the conventional treatment group had developed clinical nephropathy and more patients were receiving antihypertensive treatment, compared with the insulin infusion group $(p<0.01)$.

More patients developed proliferative retinopathy in the conventional treatment groups but the difference did not reach statistical significance. The majority of patients had normal vision at follow-up and differences in visual acuity between the groups could not be demonstrated.

The effects of improved metabolic control were observed despite of no significant differences in $\mathrm{HbA}_{1 \mathrm{c}}$ between the groups during the past three years of follow-up. This indicates a long-term effect of the very good metabolic control during the first three to five years of study. However, a trial effect in the conventional treatment groups cannot be excluded. Among the 35 patients entering the control groups of the two trials there was an overall improvement in the metabolic control. This trial effect may explain why only one patient with a urinary albumin excretion rate below $100 \mathrm{mg} / 24 \mathrm{~h}$ progressed to nephro- pathy in contrast to previous reports $[19,20]$. The observed trial effect is more clearly expressed in the multiple regression analyses of all 69 patients. Apart from the albuminuric level at entry, the most important determinant of changes in albumin excretion was glycaemic control $\left(\mathrm{HbA}_{1 \mathrm{c}}\right)$ during study. This association between long-term glycaemic control and progression of markers of microangiopathy supports previous observations [21-26]. Because of so many patients with microalbuminuria being stable or even normalizing their albumin excretion during five years observation no significant increase in urinary albumin excretion was observed in the control group of Steno Study 2 . This may explain why this study did not add any new information from the second to the fifth year of follow-up.

The six cardiovascular events were all but one in patients receiving conventional treatment. The one patient from the insulin infusion group had changed to multiple injection treatment after two years and the metabolic control had been poor for the past six years with a mean $\mathrm{HbA}_{1 \mathrm{c}}$ of $10.1 \%$. The study populations were, however, too small to allow for any conclusions regarding cardiovascular mortality and near-normal metabolic control.

Patients are at an increased risk of ketoacidosis during treatment with insulin infusion pumps [27, 28]. In this study three patients died during ketoacidosis while being treated with insulin infusion pumps. The cause of death could not be diagnosed exactly. All were males, two of them living alone. One was recently divorced and undergoing psychiatric therapy after an attempt to commit suicide. One had proliferative retinopathy with a rapidly reduced vision and had consequently lost his job. In the third case autopsy indicated severe cardiomyopathy. Pump failure was excluded by several tests on post mortem examination. All patients had been thoroughly educated in their treatment and were expected to be able to cope with any situation preceeding ketoacidosis. The fact that they eventually did not, calls for more intensive education and re-education of patients, families and doctors. It may also call for re-evaluations of the feasibility of this kind of intensified treatment. The observed frequency of ketoacidosis in our study is similar to that reported by other groups [29-33]. Despite an increased risk of ketoacidosis and of hypoglycaemia, the treatment with infusion pumps has been considered safe and not associated with excess mortality in 3500 patients selected for this treatment in the USA in 1982 [34].

Early antihypertensive treatment is of importance for the rate of decline of the glomerular filtration rate [36, 37] as well as for increasing the life expectancy of Type 1 diabetic patients with nephropathy $[38,39]$. This study suggests that in the future patients at risk of nephropathy should also be offered near-normal metabolic control, if necessary by means of intensified insulin treatment regimens, in order to preserve their kidney function.

Acknowledgements. This work was supported by the Nordic Insulin Foundation, the J. and O. Juhl's Foundation, the Michaelsen Foundation, the Health Organisation "Denmark", the B. and M. Klein Foundation, the Danish Diabetes Association and the Danish Medical Research Council. The technicians Mrs. M. Deckert and Mrs. H. Foght are gratefully thanked for their assistance. 


\section{References}

1. Lauritzen T, Frost-Larsen K, Larsen HW, Deckert T, Steno Study Group (1985) Two years' experience with continuous subcutaneous insulin infusion in relation to retinopathy and neuropathy. Diabetes 34 [Suppl 3]: 74-79

2. Feldt-Rasmussen. B, Mathiesen ER, Deckert T (1986) Effect of two years of strict metabolic control on progression of incipient nephropathy in insulin-dependent diabetes. Lancet II: $1300-1304$

3. Beck-Nielsen $\mathrm{H}$, Richelsen B, Mogensen CE, Olsen T, Ehlers N, Nielsen CB, Charles P (1985) Effect of insulin pump treatment for 1 year on renal function and retinal morphology in patients with IDDM. Diabetes Care 8:585-589

4. Wiseman M, Saunders AJ, Keen H, Viberti GC(1985) Effect of blood giucose control on increased glomerular filtration rate and kidney size in insulin-dependent diabetes. N Engl J Med 312: 617-621

5. Bending JJ, Viberti GC, Watkins PJ, Keen H (1986) Intermittent clinical proteinuria and renal function in diabetes: evolution and the effect of glycaemic control. Br Med J 292: 83-86

6. Raskin P, Pietri AO, Unger R, Shannon WA (1983) The effect of diabetic control on the width of skeletal-muscle capillary basement membrane in patients with type 1 diabetes mellitus. N Engl J Med 309: 1546-1550

7. Viberti GC, Bilous RW, Mackintosh D, Bending JJ, Keen H (1983) Long-term correction of hyperglycemia and progression of renal failure in insulin-dependent diabetes. Br Med J 286: 598 602

8. Davies AG, Price DA, Houlton CA, Burn JL, Fielding BA, Poslethwaite RJ (1984) Continuous subcutaneous insulin infusion in diabetes mellitus. Arch Dis Child 59: 1027-1033

9. Friberg TR, Rosenstock J, Sanborn G, Vaghefi A, Raskin P (1985) The effect of long-term near normal glycemic control on mild diabetic retinopathy. Ophthalmology 92: 1051-1058

10. Dahl-Jørgensen K, Brinchmann-Hansen O, Hanssen KF, Ganes T, Kierulf P, Smeland E, Sandvik L, Aagenaes $\emptyset$ (1986) Effect of near-normo glycemia for two years on progression of early diabetic retinopathy, nephropathy and neuropathy: the Oslo Study. Br Med J 293: 1195-1199

11. Reichard P, Rosenqvist U (1989) Nephropathy is delayed by intensified insulin treatment in patients with insulin-dependent diabetes mellitus and retinopathy. J Int Med 226:81-87

12. Feldt-Rasmussen B, Mathiesen ER, Hegedüs L, Deckert T (1986) Kidney function during 12 months of strict metabolic control in insulin-dependent diabetic patients with incipient nephropathy. N Engl J Med 314: 665-670

13. Svendsen PA, Christiansen JS, Søegaard U, Welinder BS, Nerup J (1980) Rapid changes in chromatographically determined haemoglobin A1c, induced by short-term changes in glucose concentration. Diabetologia 19:130-136

14. Mancini G, Carbonara AO, Heremans JF (1965) Immunochemical quantitation of antigens by single radial immunodiffusion. Immunochemistry 2: 301-305

15. Feldt-Rasmussen B, Dinesen B, Deckert M (1985) Enzyme immunoassay - an improved determination of urinary albumin in diabetics with incipient nephropathy. Scand J Clin Lab Invest 45: 539-544

16. Broechner-Mortensen J, Giese J, Rossing N (1969) Renal insulin clearance versus total plasma clearance of ${ }^{51} \mathrm{Cr}$-EDTA. Scand J Clin Lab Invest 23: 301-305

17. Mathiesen ER, Oxenbøll R, Johansen K, Svendsen PA, Deckert $T$ (1984) Incipient nephropathy in Type 1 (insulin-dependent) diabetes. Diabetologia 26: 406-410

18. Deckert T, Lauritzen T, Parving H-H, Christiansen JS, Steno Study Group (1984) Effect of two years of strict metabolic control on kidney function in long-term insulin-dependent diabetics. Diab. Nephropathy 3: 6-10

19. Viberti GC, Hill RD, Jarrett RJ, Argyropoulos A, Mahmud U, Keen $H$ (1982) Microalbuminuria as a predictor of clinical nephropathy in insulin-dependent diabetes mellitus. Lancet I: $1430-1432$
20. Mogensen CE, Christensen CK (1984) Predicting diabetic nephropathy in insulin-dependent diabetic patients. $\mathrm{N}$ Engl $\mathrm{J}$ Med 311:89 93

21. Deckert T, Feldt-Rasmussen B, Borch-Johnsen K, Jensen T, Kofoed-Enevoldsen A (1989) Albuminuria reflects widespread vascular damage. The Steno Hypothesis. Diabetologia 32: 219-226

22. Doft BH, Kingsley LA, Orchard TJ, Kuller L, Drasch A, Becker D (1984) The association between long-term diabetic control and early retinopathy. Ophthalmology 91: 763-769

23. Weber B, Burger W, Hartmann R, Howener R, Howener G, Malchuo R, Oberdisse U (1986) Risk factors for the development of retinopathy in children and adolescents with Type 1 diabetes mellitus. Diabetologia 29: 23-29

24. Nørgaard K, Storm B, Graae M, Feldt-Rasmussen B (1989) Elevated albumin excretion and retinal changes in children with type 1 diabetes are related to long-term poor metabolic control. Diabetic Medicine 6: 325-328

25. McCane DR, Atkinson AB, Hadden DR, Archer DB, Kennedy $\mathrm{L}$ (1989) Long-term glycaemic control and diabetic retinopathy. Lancet II: 824-828

26. Nyberg G, Blohmé G, Nordén G (1987) Impact of metaboliccontrol in progression of clinical diabetic nephropathy. Diabetologia 30: $82-86$

27. Rønn B, Mathiesen ER, Vang L, Lørup B, Deckert T (1987) Evaluation of insulin pump treatment under routine conditions. Diab Res Clin Pract 3: 191-196

28. Snorgaard O, Eskildsen PC, Vadstrup S, Nerup J (1982) Epidemiological aspects of diabetic ketoacidosis in Denmark (Copenhagen county). Acta Endocrinol 100 [Suppl 247]: 56A

29. Knight G, Boulton A JM, Drury J, Gamsu DS, Moses JL, Bradley C, Ward JD (1984) A feasibility study of the use of continuous subcutaneous insulin infusion in a diabetic clinic: patients' choice of treatment, Diab Med 1:267-272

30. The Kroc Collaborative Study Group (1984) Blood glucose control and evaluation of diabetic retinopathy and albuminuria. $\mathrm{N}$ Engl J Med 6:365-372

31. Peden NR, Braaten JT, McKendry R (1984) Diabetic ketoacidosis during long-term treatment with continuous subcutaneous insulin infusion. Diabetes Care 7:1-5

32. Mecklenburg RS, Benson EA, Benson JW et al. (1984) Acute complications associated with insulin infusion pump therapy. $J$ Am Med Assoc 252: 2365-2369

33. Sonnenberg GE, Mühlhauser I, Chantelau E, Berger M (1985) Incidence of ketoacidosis and severe hypoglycaemia in conventional and CSII treated Type 1 diabetic patients. Diabetes 34 [Suppl 1]:34A

34. Teutsch SM, Herman WH, Dwyer DM, Lane JM (1987) Mortality among diabetic patients using continuous subcutaneous insulin infusion. $\mathrm{N}$ Engl J Med 310: 361-368

35. DCCT Study Group (1987) Diabetes Control and Complications Trial (DCCT): Results of feasibility study. Diabetes Care 10: 119

36. Mogensen CE (1982) Long-term antihypertensive treatment inhibiting progression of diabetic nephropathy. Br Med J 285: $658-688$

37. Parving H-H, Andersen AR. Smidt UM, Hommel E, Mathiesen ER, Svendsen PAa (1987) Effect of antihypertensive treatment on kidney function in diabetic nephropathy. Br Med J 294: $1443-1447$

38. Mathiesen ER, Borch-Johnsen K, Jensen DV, Deckert T (1989) Improved survival in patients with diabetic nephropathy. Diabetologia 32: $884-886$

39. Parving H-H, Hommel E (1989) Prognosis in diabetic nephropathy. Br Med J 299: 230-233

Received: 14 May 1990

and in revised form: 10 September 1990

Dr. B.Feldt-Rasmussen

Steno Memorial Hospital

Niels Steensensvej 2

DK-2820 Gentofte

Denmark 